\title{
Research on public opinion risk control of "one belt and one road"
}

Zou Wenjun, Lan Yuexin, Xia Yixue, Liu Mo, Zhang Peng

China People's Police University

Langfang, China

892955831@qq.com

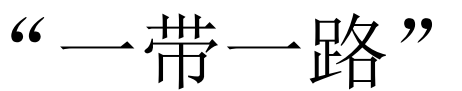

舆情风险管控研究

邹汶君 兰月新 夏一雪 刘茉 张鹏

中国人民警察大学

廊坊 065000 , 中国

892955831@qq.com

Abstract-In this paper, Hierarchical 带一路” 沿线国家涉华舆情风险要素, 构建 Holographic Modeling is adopted for risk modeling. Based on the case study of china-related public opinions in countries along the "One Belt And One Road" line, risk factors related to china-related public opinions in countries along the "One Belt And One Road" line are analyzed more comprehensively, and corresponding countermeasures are proposed according to the risk level, so as to provide a more scientific and effective decision-making reference for countries to better promote the "One Belt And One Road" initiative.

Keywords - Hierarchical Holographic Modeling; One Belt And One Road;public opinion on china;risk

摘要一本文采用 HHM 等级全息建模方法进行 风险建模, 以 “一带一路” 沿线国家涉华舆情相关 案例为研究依据, 更全面地分析与 “一带一路” 沿 线国家涉华舆情有关的风险因素, 并依据风险等级 提出相应对策, 为国家更好的推进 “一带一路” 倡 议提供更科学、有效的决策参考。

关键词一HHM 模型, 一带一路, 涉华舆情, 风险

\section{I. 引言}

“一带一路” 倡议提出以来, 沿线国家 涉华舆情一直深刻影响着 “一带一路” 倡议 的战略发展和政策环境, 因此准确识别 “一 


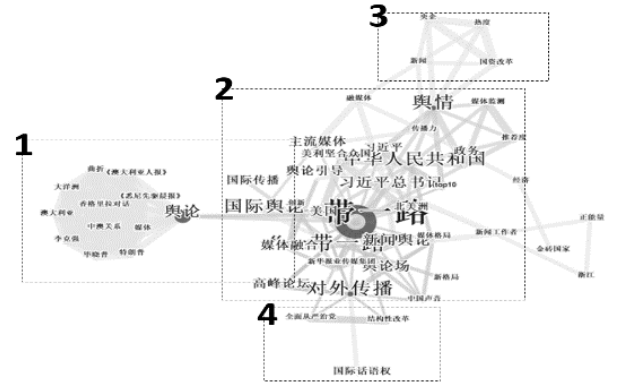

图 1 关键词共现分析网络
注: 检索式为: 主题= “一带一路 and 與情” or “一带一路 and 與论”，检索年限限定为 2014 年 1 月 1 日至 2018 年 5 月 1 日，检索时间为 2018 年 5 月 1 日, 数据库来源选择: 核心期刊 + CSSCI 来源期 刊

表 1 “一带一路” 倡议舆情方面研究视角

\begin{tabular}{|c|c|c|c|}
\hline 视角 & 区域 & 涉及关键词 & 切入点 \\
\hline 国际关系 & 1 & $\begin{array}{l}\text { 国际與论、中澳 } \\
\text { 关系、曲折、美国、香 } \\
\text { 格里拉对话、特朗普等 }\end{array}$ & $\begin{array}{l}\text { 基于国际关系视角进行研究, 将“一带一路” } \\
\text { 涉华與情看作国际关系的反映，根据相关與情， } \\
\text { 分析该时间段内的国际关系及趋势 }{ }^{[2-9]} \text { 。 }\end{array}$ \\
\hline 传播学 & 2 & $\begin{array}{l}\text { 对外传播、媒体 } \\
\text { 融合、主流媒体、媒体 } \\
\text { 监测、舆论引导等 }\end{array}$ & $\begin{array}{l}\text { 基于新闻传播学视角进行研究, 将 “一带一 } \\
\text { 路” 涉华與情分类探讨并针对性的提出传播建议 } \\
\text { [4,10-13]。 }\end{array}$ \\
\hline 经济学 & 3 & $\begin{array}{l}\text { 央企、国资改革、 } \\
\text { 经济等 }\end{array}$ & $\begin{array}{l}\text { 基于经济学视角进行研究, 着重分析 “一带 } \\
\text { 一路” 倡议实施环境及实施过程中对国内及合作 } \\
\text { 国家的经济方面的影响 }{ }^{[1,7,11]} \text { 。 }\end{array}$ \\
\hline 政治学 & 4 & $\begin{array}{l}\text { 国际话语权、全 } \\
\text { 面从严治党等 }\end{array}$ & $\begin{array}{l}\text { 基于政治学进行研究, 主要是对相关政 } \\
\text { 策及其影响进行解读 }{ }^{[10-12]} \text { 。 }\end{array}$ \\
\hline
\end{tabular}

目前我国学者已经从舆情方面对“一带一 路” 倡议进行了多个视角的研究, 主要包括: 国际关系、传播学、经济学、政治学。其中国 际关系和传播学方面研究较深入、分支较广， 因为 “经济学”与 “政治学”与本次研究无关, 所以本文将着重对 “国际关系”、“传播学” 视 角进行分析。

1 区从国际关系角度, 集中分析国外对中 国 “一带一路” 倡议的舆论方向: 第一, 沿线 国家对中国 “一带一路” 倡议持矛盾的态度， 一方面经济上积极合作, 对倡议给予肯定, 另 一方面担心中国会对其国家政治构成威胁 ${ }^{[2-4]}$ 。 第二, 国际舆论对 “一带一路” 倡议仍存在一 定程度的误解, “中国的崛起将会控制全球的 经济” 等论调层出不穷 ${ }^{[5-7]}$ 。针对这些舆论, 国 际关系角度的文献提出了理性应对、坚持价值 标准和自信等对策 ${ }^{[3-4,8-9]}$ 。国际关系方面在情 报搜集、分析所用的时间较长, 消息的滞后会 错过與情应对黄金期。

2 区从传播学方面, 针对国际舆论提出新
闻宣传报道方面的建议: 第一, 以多家媒体的 新闻报道为研究对象, 分析我国主流媒体 “一 带一路” 新闻舆论工作的现状 ${ }^{[10]}$ 。第二, 新时 期网络舆情传播呈现新的特征, 塑造良好社会 形象, 正确利用社会团体、意见领袖的影响, 引导舆论正确发展。 ${ }^{[11]}$ 。第三, “一带一路” 倡 议推进过程中处理与美俄印三国关系应该对 “一带一路”进行正面宣传, 尽量避免使用“战 略”、“计划” 等敏感、侵略性词语, 以免对地 缘政治造成不利影响 ${ }^{[4,12-13]}$ 。传播学方面的方 法针对对外报道是极其有效的，但是在应对涉 华與情方面就显得十分被动, 针对这一不足本 文致力于为将被动变为主动提出对策。

综合以上两区的研究内容, “一带一路” 沿线国家涉华與情仍然需要进一步探索, 基于 此, 本文在定性研究 “一带一路” 沿线国家涉 华舆情的基础上, 通过 HHM 模型探讨 “一带一 


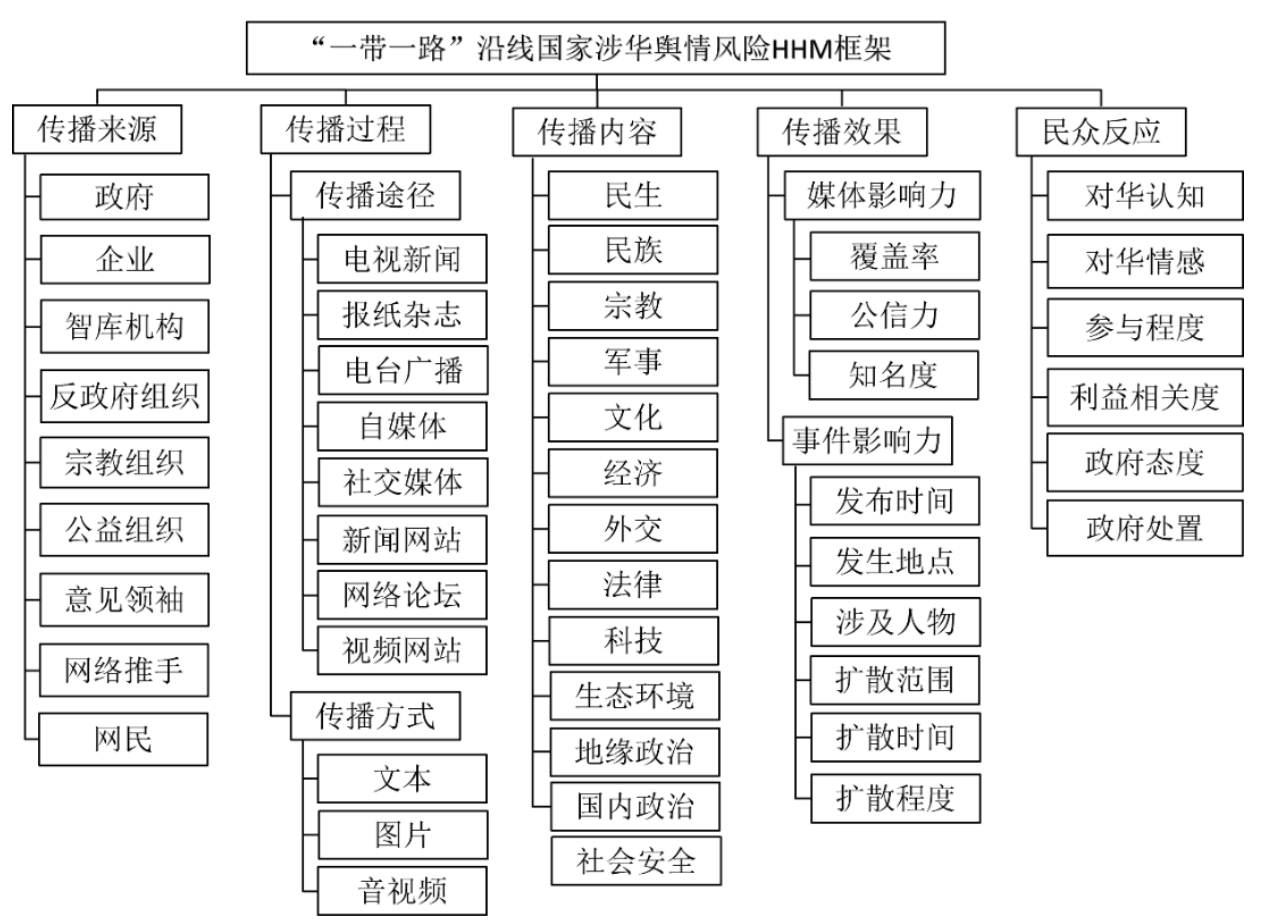

图 2 “一带一路” 沿线国家涉华舆情相关主体及其活动的 HHM 框架

路”沿线国家涉华與情风险要素及我国政府应 对相关與情的策略, 为政府能够更快、更好应 对相关舆情提供决策思路, 以期保证 “一带一 路” 倡议顺利推进。

\section{III. “一带一路”沿线国家涉华舆情风险建模}

随着国家的强大与进步，中国国际话语 权显著增强, “中国方案”越来越受到国际社 会的关注, 基于著名传播学者拉斯韦尔曾提 出 “ $5 W$ 模式” 理论, 即传播主体 (who) 、传 播内容 (Says What)、传播渠道 (In Which Channe1)、传播客体 (To Whom) 、传播效果 (With What Effect ) ${ }^{[21]}$, 以及 “一带一路” 沿线国家涉华與情实际情况，提出传播来 源、传播过程、传播内容、传播效果和民众 反应五大影响要素。

\section{情风险要素分析}

“一带一路” 倡议机遇与挑战并存, 面 对相关涉华與情我们必须谨慎对待。“一带一 路” 沿线国家涉华與情对我国存在的风险隐 患主要包括新疆社会治安问题、恐怖主义、 极端势力 ${ }^{[17]}$ 等安全风险, 中国经济模式与合 作国家本土经济模式相碰撞的政治和经济风 险, 以及网络传播的不可控性和政府消息的
滞后性。本文在此基础上, 在反复迭代的过 程中确定不同主题在 “一带一路” 沿线国家 涉华與情中的风险要素 (见图 2)。

1) 传播来源要素识别

“一带一路” 倡议的政策性质以及 “人 类命运共同体” 的提出，使地球村中各个国 家的联系越来越密切, 尤其是中国国际地位 提升后, 中国的一言一行备受瞩目, 因此 “一带一路” 倡议变成了全球热议的话题, 传播来源多样化。

2) 传播过程要素识别

自 2013 年我国新媒体、社交媒体发展迅 速, 为信息传播提供了更多途径, 使信息的 获取更加方便快捷, 新增的视频、音频等传 播方式, 增加了信息的可读性, 使涉华與情 更容易被理解，同时传统主流媒体为信息增 加了 “权威性” , 由主流媒体发布的舆论更 容易被公众相信, 因此由主流媒体发布的负 面舆情更容易引起民众的负面情绪。

3) 传播内容要素识别

西方国家长期掌握话语权，面对中国的 崛起, 西方很长一段时间难以适应, 以西方 为主导的與情仍以曲解、质疑为主, 内容涉 及文化、宗教、恐怖主义等多个方面, 且不 当與论、负面情绪极易引发與情事件。

4) 传播效果要素识别 
由涉华舆情热度持续时间来看, 传播效 果既反映国外媒体的关注点, 也反应国外群 众的对华认知和情感，既能反映媒体影响 力, 又能透析发布环境。用户关注度高的媒 体，其发布的與论更容易被用户评论和转 发。

5) 民众反应要素识别

舆情的最终反映形式是民众的反应，负
面报道会引导公众情绪向极端的方向发展, 尤其是当政府对相关與情敏感度低、反应速 度慢，更会促使负面與情爆发式增长。

\section{IV. 风险量化与评级}

构建 “一带一路”沿线国家涉华與情风 险框架之后, 需要对风险因素进行量化和评 级, 以便为决策建议的提出提供优先次序。

表 2 “一带一路” 沿线国家涉华舆情风险指标体系

\begin{tabular}{|c|c|c|}
\hline 一级指标 & 二级指标 & 三级指标 \\
\hline \multirow[t]{3}{*}{ 传播来源 Fl } & & 反政府组织 F111,政府 F112,网民 F113, 智库机构 F114, 网 \\
\hline & & 络推手 F115,宗教组织 F116,公益组织 F117,意见领袖 \\
\hline & & F118,企业 F119 \\
\hline \multirow[t]{5}{*}{ 传播过程 F2 } & 传播途径 F21 & 网络论坛 F211,视频网站 F212, 电台广播 F213,自媒体 \\
\hline & & F214, \\
\hline & & 报纸杂志 F215,社交媒体 F216,新闻网站 F217, 电视新闻 \\
\hline & & F218 \\
\hline & 传播方式 F22 & 文本 F221,图片 F222,音视频 F223 \\
\hline \multirow[t]{4}{*}{ 传播内容 F3 } & & 经济 F311,法律 F312,外交 F313, 科技 F314, 民生 F315,民 \\
\hline & & 族 F316,军事 F317, 宗教 F318, 文化 F319,生态环境 F320, \\
\hline & & 国内政治 F321, \\
\hline & & 地缘政治 F322,社会安全 F323 \\
\hline \multirow[t]{3}{*}{ 传播效果 F4 } & 事件影响力 F41 & 发布时间 F411,发生地点 F412,涉及人物 F413 \\
\hline & & 扩散范围 F414,扩散时间 F415,扩散程度 F416 \\
\hline & 媒体影响力 F42 & 知名度 F421,公信力 F422,覆盖率 F423 \\
\hline \multirow[t]{2}{*}{ 民众反应 F5 } & & ,政府处置 F521,政府态度 F522,利益相关度 F523 \\
\hline & & 参与程度 F524,对华情感 F525，对华认知 526 \\
\hline
\end{tabular}

通过帕累托分析法 ( Activity Based Classification) 对所有风险因素进行分级: 首先将三级指标按综合权重降序排序; 然后计 算权重累计占比; 最后将累计占比分级, $0 \%-$ $60 \%$ 为高级风险, $60 \%-85 \%$ 为中级风险, $85 \%-100 \%$ 为低级风险。

分析得出高级风险 11 个, 中级风险 13 个, 低级风险 24 个, 其中高级风险因素为利益相关 度、对华情感、政府处置、参与程度、政府态 度、公信力、涉及人物、扩散程度、地缘政治、 发布时间、对华认知, 这 11 个风险因素应是“一 带一路” 沿线国家涉华舆情风险管理的重点, 我国舆情管理部门应着重做好针对这些风险 因素的应对策略。其次是中级风险, 包括扩散 范围覆盖率、知名度、电台广播、扩散时间、 民生、民族、发生地点、音视频、意见领袖、 科技、政府、经济。低级风险包括: 宗教、国 内政治、社会安全、图片、社交媒体、军事、 报纸杂志、文化、新闻网站、外交、反政府组 织、网络推手、宗教组织、生态环境、自媒体、
电视新闻、文本、网络论坛、企业、智库机构、 视频网站、法律、公益组织、网民。

V. “一带一路” 沿线国家涉华與情风险防范 对策研究

“一带一路”沿线国家涉华舆情具有传 播主体区域化、报道态势多元化、国内外共 鸣去中心化等特点, 为了适应当前国际环 境，根据前文提出的 “一带一路” 沿线国家 涉华與情风险防范思路，本文针对 11 个高级 风险因素提出风险防范对策。

\section{A. 合理利用外媒, 促成舆情的自} 我矫正：针对传播内容中的高级风险采取 的对策

“一带一路”倡议使更多国家进一步认 识中国、了解中国, 但是由于意识形态、立 场等方面的不同，外媒对中国 “一带一路” 
倡议的认识存在明显差异, 某些外媒缺少权 威的信息来源, 报道内容失真, 如果我国不 能很好的利用外媒, 那么国外舆论会更倾向 于传播负面信息，从而影响我国的国际形 象。

首先, 对 “一带一路” 沿线国家的报道 内容应给予足够的关注。“一带一路” 沿线国 家是 “一带一路” 倡议最直接的受益国, 大 部分国家对倡议持肯定态度, 但是一旦出现 负面涉华舆情对我国的影响将是极大的, 因 此我们应重点关注 “一带一路” 沿线国家的 报道内容, 实时监测、及时分析, 了解 “一 带一路” 沿线国家民众情绪, 适当调整传播 重点。

其次, 参与角色不同, 引导策略不同。 “一带一路” 沿线国家涉华與情传播内容涉 及政治、经济、宗教等多个内容, 我国的引 导策略应根据與情类别作出适当调整, 例如 在面对涉及我国地缘纠葛的内容时, 应大力 宣传倡议带来的经济利益和安全保障, 打破 信任壁垒, 确保倡议顺利推进。

最后，新政策出台后应及时召开发布 会, 实施有效的口径管理。要坚持与媒体统 一战线的思想。新政策发布后及时向基层工 作者及国内外媒体传达政策中心思想, 使外 界及时了解新政策的决策思路及带来的福 利, 可以最大程度避免歪曲解读和报道。

\section{B. 第一时间发声, 引导舆论秩序 恢复: 针对传播效果中的高级风险采取的 对策}

快节奏的生活使人们对信息新鲜度要求 较高, 面对不确定的事件, “谁第一个发声, 谁就是知情者” 的心理让网民被各种虚假信 息迷惑, 因此涉华與情事件发生后必须做到 第一时间发声、第一时间处理, 这样才能掌 握话语主导权。

首先, 抢占时机, “第一时间” 作出反 应。第一时间掌握话语权, 对于引导民意、 化解危机, 具有十分重要的作用。这不仅需 要我们具有與情敏感性还需要我们实时监测 网络與情, 做到早发现、早处置, 争取在萌 芽状态就掌握主动权, 正面引导公众情绪。

其次, 借力意见领袖让正面與论占上 风。意见领袖往往对與论有着不可忽视的引
导作用, 利用新闻发布会, 媒体工作者座谈 会, 加强意见领袖培养, 让他们准确了解我 国政策的决策意图, 利用他们的网络影响力 传播正能量, 充分发挥他们的與论引导作 用。

最后, 主动发布避免受到社会舆论左 右。通过对近几年涉华與情的分析, 我们发 现在與论压力下发布的事件处理结果往往无 法令传播受众满意, 因此我国政府必须主动 发布事件处理进展, 及时表态, 树立积极负 责的形象。

\section{C. 态度决定成败, 增强国外民众 安全感: 针对民众反应中的高级风险提出 的对策}

舆情的出现必然会带来民众情绪的波 动, 而政府的态度往往会对民众情绪激化或 缓和造成直接影响, 面对负面涉华舆情, 诚 恳的态度往往体现的是一个国家的责任与担 当, 了解民众意愿, 用实际行动解决问题有 利于重塑我国良好的国际形象。

首先, 精准把握民众利益相关做到知民 亲民。“一带一路” 沿线国家大多是民意国 家, 民意在国家政权中起着举足轻重的作 用, 因此我国相关政策的提出应考虑到实施 国民众的利益相关, 通过实地考察等方式了 解民众意愿, 精准把握民众利益相关, 为后 续的政策和宣传提供参考。

其次, 态度真诚, 积极回应, 妥善处 理。面对国外民众的激烈情绪, 如果能打出 感情牌, 拉近与民众之间的距离, 以人为本 以情动人, 给公众以情感修复, 往往能够获 得與论理解与支持, 在此基础上, 积极解答 民众疑惑, 妥善处理事件后续, 从而增强国 外民众安全感。

最后, 借助與情修正决策。面对涉华與 情, 重点在 “预”, 对與情进行预警, 对民意 进行预判, 对波动进行预防, 所以提高政府 防御能力的重点是做好 “预”。但在與情发生 之后, 我们除了安抚民众情绪, 最重要的是 解决事件背后凸显的问题, 尤其是 “一带一 路” 沿线国家涉华與情涉及到国家政策, 相 关政策的提出是否顺应民意是否符合该国人 民根本利益, 我们可以从與情中看出一二, 因此借助與情修正决策可以使决策更科学。 
VI. 研究结论

“一带一路” 倡议的持续推进得到许多 国家的积极响应, 在倡议推进的过程中, 程 度不同、影响力不同的涉华舆情, 在政治、 经济、民生等领域对我国产生的影响也不 同, 因此面对不同的传播来源、传播内容我 们采取的应对措施也不尽相同。通过 “一带 一路” 涉华與情案例的检验可以发现, 本文 构建的 “一带一路”沿线国家涉华舆情风险 模型是具有可行性, 并且通过风险点和案例 提出的决策建议可以更有针对性地摸索对外 传播的重点, 以营造良好的與论环境。

致谢

本项目受到教育部人文社会科学研究青年基 金项目““一带一路”沿线国家涉华舆情风险预警与 决策支持研究”（编号：17YJC860010）的资助。

\section{参考文献}

[1] 阳阳. “海丝” 合作下的越南交通基建需求与與论态 度 $[J]$. 南海学刊, (3) : 91-99.

［2］宁洪波.浅析印度在孟买恐怖袭击案中的情报失误 [J]. 科技情报开发与经济, 2012，（18）: 96-99.

[3] 周宏刚. 从国际與论的形成机制看 “一带一路” 的传 播策略一以印度主流英文报纸的报道为例 $[\mathrm{J}]$. 新闻 知识, 2017, (03) :7-11.

[4] 杨思灵. “一带一路” 印度的回应及对策 $[J]$. 亚非纵 横, 2014, (06) : 51-60+1-127+132.

[5]周萃, 康健. 美国主流媒体如何为 “一带一路” 构建 媒介框架 [J]. 现代传播 (中国传媒大学学报), 2016, (06) : 163-165.

［6］仇华飞. 美国学者视角下的中国 “一带一路” 构想 $[J]$. 国外社会科学, 20, (06) : 49-57.

[7] 李红岩. 美国涉华利益集团的新变化 $[J]$. 现代国际关 系, 2007, (10) : 26-30

[8］胡雅娟. 打破 “沉默的螺旋”: “卫星” 通讯社报道手 法浅析一一兼论 “卫星” 通讯社与西方媒体涉华报 道异同 [J]. 对外传播, 2017, (04) : 77-78.

[9] 朱龚星, 朱金平. 理性对待西方涉华與论 $[J]$. 军事记 者, 2017, (10) : 30-31.

[10］赵明吴. “一带一路” 的政策传播: 问题与应对 [J]. 对外传播, 2016 (04) : 23-25+1.
[11］舒欢. “一带一路” 重大工程建设正面形象的與论 营造研究 [J]. 南京社会科学, 2016, (11) : 151-156.

[12］欧阳向英. 季塔连科：俄罗斯涉华问题国家级智囊 [J]. 对外传播, 2010, (09):61-62.

[13］毛楚众. 俄罗斯反恐情报体系的历史演进 $[J]$. 黑河 学刊, 2017, (5) :84-86.

[14］朱晓军. 中国 “一带一路” 倡议的国际舆论环境分 析 [J]. 新媒体与社会, 2017, (04):9-23.

[15］孙敬金金. “一带一路” 建设面临的国际與论环境 [J]. 当代世界, 2015, (04): 18-20.

［16］郭可, 杨文睿. 新战略期国际涉华舆情新特征和舆 论引导新态势 $[J]$. 对外传播, 2016, (12) :4-6.

[17］龚婷. “一带一路” 国际舆论反应初探及应对建议 [J]. 对外传播, 2015, (03)：24-26.

[18］兰月新，董希琳，邓新元等. 基于 HHM 的公共危机 事件网络與情风险管理研究 [J]。情报杂志, 2014, $3(10): 33-38,7$.

[19］赵磊. 一带一路观察 | 中央党校赵否: “一带一 路” 造 “债权危机”？[EB/OL]．搜狐．2018-08-0 7. http://www. sohu. com/a/245761042_610982.

［20］李俊亮. 年终系列 | 2017 年外媒涉 “一带一路” 與情态势 [EB/0L]. 2017-12-21. http://mp. weixin. qq. com/s/r9_fzVYsgDYTMOA2YBwcqw.

[21］于鹏亮. 传播学视域下我国网络流行语的 “5W” 模 式分析 [J]. 东南传播, 2018(06):54-56.

[22］陈悦, 陈超美, 刘则渊, 胡志刚, 王贤文. CiteSpace 知 识图谱的方法论功能 [J]. 科学学研究, 2015, 33 (02) : 242253 